\title{
НАНОЧАСТИЦЫ СПОСОБНЫ НАПРАВЛЯТЬ ТРАНСПЛАНТИРОВАННЫЕ МЕЗЕНХИМАЛЬНЫЕ СТВОЛОВЫЕ КЛЕТКИ В ПОСТТРАВМАТИЧЕСКИЙ СВИЩ У КРЫС С ПОВРЕЖДЕНИЯМИ СПИННОГО МОЗГА
}

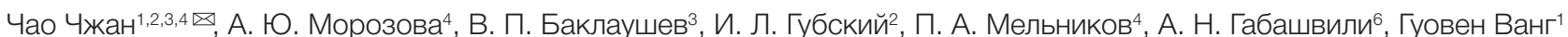
Лили Ли ${ }^{1}$, Хайсяо Уํㅜ, Ксин Ванг ${ }^{5}$, В. П. Чехонин ${ }^{2,4}$

Кафедра опухолей костей и мягких тканей, Онкологический институт и госпиталь Тяньцзиньского медицинского университета, Национальный клинический исследовательский центр рака, Главная лаборатория профилактики и лечения рака, Тяньцзиньский клинический исследовательский центр рака, Тяньцзинь, Китай 2 Кафедра медицинской нанобиотехнологии, Российский национальный исследовательский медицинский университет имени Н. И. Пирогова, Москва

${ }^{3}$ Федеральное медико-биологическое агентство, Москва

${ }^{4}$ Национальный медицинский исследовательский центр психиатрии и наркологии имени В. П. Сербского, Москва

${ }_{5}^{5}$ Кафедра эпидемиологии и биостатистики, Первая больница медицинского университета Сухопутных войск, Чунцин, Китай

${ }^{6}$ Институт общей генетики имени Н. И. Вавилова РАН, Москва

\begin{abstract}
Травма спинного мозга (ТСМ) - это травматическое повреждение, не являющееся следствием заболевания. Мезенхимальные стволовые клетки (МСК) становятся одним из наиболее используемых типов стволовых клеток как в научных исследованиях, так и в клинических испытаниях. С учетом предыдущих работ, в которых использовали от $4 \cdot 10^{5}$ до $1 \cdot 10^{6}$ кл., целью данного исследования было определить количество МСК, оптимальное для трансплантации при хронической ТСМ. Магнитные наночастицы (НЧ) использовали для доказательства точности проведенной трансплантации. С помощью магнитно-резонансной томографии (MPT), диффузионно-тензорной визуализации (DTI), диффузионно-тензорной трактографии (DTT) и поведенческих тестов мы проверили влияние различного количества MCK на уменьшение пораженной полости и посттравматического свища, подавление формирования глиального рубца, усиление ремоделирования нейронных волокон, содействие регенерации и прорастанию аксонов, улучшение васкуляризации, повышение уровня экспрессии нейронных факторов и улучшение функционирования системы. Магнитные НЧ были точно трансплантированы в посттравматический свищ (ПТС). МСК могут восстанавливать функцию после хронической ТСМ посредством стимуляции регенерации и прорастания аксонов, уменьшая образование ПтС. Таким образом, влияние МСК на ПТС и функциональное улучшение после хронической ТСМ зависит от количества клеток, и в диапазоне от $4 \cdot 10^{5}$ до $1 \cdot 10^{6}$ наилучшей дозой является $1 \cdot 10^{6}$.
\end{abstract}

Ключевые слова: мезенхимальные стволовые клетки; травма спинного мозга; трансплантация клеток; наночастицы Финансирование: исследование поддержано Китайским стипендиальным советом (№ 201406940004) и Российским научным фондом (№ 16-15-10432).

$\varangle$ Для корреспонденции: Чао Чжан

ул. Хуанху Си, Район Хэси, Тяньцзинь, Китай, 300060; drzhangchao@tmu.edu.cn

Статья получена: 26.08.2018 Статья принята к печати: 25.09.2018

DOI: $10.24075 /$ vrgmu.2018.084

\section{NANOPARTICLES GUIDED PRECISE TRANSPLANTATION OF VARYING NUMBERS OF MESENCHYMAL STEM CELLS INTO POST-TRAUMATIC SYRINX IN SPINAL CORD INJURY RAT}

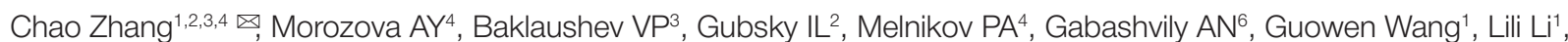
Haixiao Wu ${ }^{1}$, Xin Wang ${ }^{5}$, Chekhonin VP2,4

' Department of Bone and Soft Tissue Tumors, Tianjin Medical University Cancer Institute and Hospital, National Clinical Research Center for Cancer, Key Laboratory of Cancer Prevention and Therapy, Tianjin's Clinical Research Center for Cancer, Tianjin, China

2 Department of Medicinal Nanobiotechnology, Pirogov Russian National Research Medical University, Moscow

${ }^{3}$ Federal Research and Clinical Center, Moscow

${ }^{4}$ Federal Medical Research Center for Psychiatry and Narcology, Moscow

5 Department of Epidemiology and Biostatistics, First Affiliated Hospital, Army Medical University, Chongqing, China

${ }^{6}$ Vavilov Institute of General Genetics Russian Academy of Sciences, Moscow

Spinal cord injury (SCl) is a traumatic injury to the spinal cord which is not a consequence of the disease. Mesenchymal stem cells (MSCs) have gradually become one of the most used stem cells in research and clinic trial. Based on the previous reports employed the cells ranged from $4 \cdot 10^{5}$ to $1 \cdot 10^{6}$, the present study was performed to figure out the best number of MSCs for transplantation of the chronic SCl. Magnetic nanoparticles were used for proving the precise transplantation strategy. Using magnetic resonance imaging (MRI), diffusion tensor imaging (DTI), diffusion tensor tractography (DTT), and behavior testing evaluations, we focused the effect of varying numbers of MSCs on reducing lesion cavity and post-traumatic syrinx formation, suppressing glial scar formation, enhancing neuronal fibers remodeling, promoting axonal regeneration and sprouting, improving vascularization, ameliorating the neuronal factors expressional level, and function improvement. Magnetic nanoparticles were precisely transplanted into the posttraumatic syrinx (PTS). MSCs can restore function after chronic SCl through stimulating the regeneration and sprouting of the axons, reducing the formation of PTS. The effect of MSCs on PTS management and functional improvement post chronic SCl was cell number-dependent, and within the range of $4 \cdot 10^{5}$ to $1 \cdot 10^{6}, 1 \cdot 10^{6}$ cells were proved to be the best dose.

Keywords: mesenchymal stem cells; spinal cord injury; cell transplantation; nanoparticles

Funding: the present study was sponsored by China Scholarship Council (201406940004), and Russian Scientific Foundation (16-15-10432).

$\triangle$ Correspondence should be addressed: Chao Zhang

Huanhu Xi Road, Hexi Area, Tianjin, China, 300060; drzhangchao@tmu.edu.cn

Received: 26.08.2018 Accepted: 25.09.2018

DOI: 10.24075/brsmu.2018.084 
По результатам эпидемиологических исследований, в Китае растет число травм спинного мозга, достигая 23,7 случаев на миллион человек в год [1]. По последним данным, это значение колеблется от 9,2 до 246 случаев на миллион [2]. Почти половина случаев приводит к полной потере проведения нервного импульса в области ниже уровня травмы. Расходы на медицинское обслуживание в течение первого года для пациентов с тетраплегией и параплегией оставляют более чем 800000 и 300000 долларов США соответственно [3]. В последнее время уровень смертности в первый год после травмы неуклонно снижается. Тем не менее ТСМ по-прежнему относится к неизлечимым состояниям [4].

Патофизиологию ТСМ можно определить как двухфазный процесс: 1) первичная фаза включает начальное механическое повреждение; 2) отсроченная вторичная фаза характеризуется активацией воспаления, разрушением сосудов, ишемией, окислительным стрессом и экситотоксичностью [5-6]. Вторичная фаза подразделяется на немедленную, острую, промежуточную и хроническую стадии ТСМ [5]. Основными признаками хронической ТСМ служат глиальный рубец и формирование полости после потери функции [7-8].

Трансплантация стволовых клеток на сегодняшний день является распространенным методом лечения TCM. Первое описание применения мезенхимальных стволовых клеток (МСК) было опубликовано в 1991 г. [9] и постепенно MSC стали одним из наиболее используемых методов клеточной терапии в хирургии. Был проведен ряд исследований по трансплантации МСК при ТСМ [11-16]. Растущее число клинических испытаний использования MCK для лечения ТСМ указывает на быстрое внедрение данной технологии в клиническую практику, несмотря на ряд нерешенных вопросов, требующих прояснения как на фундаментальном, так и на доклиническом уровнях исследований [10].

Для успешного внедрения МСK в клиническую практику необходимо ответить на следующие вопросы: каковы оптимальные сроки трансплантации, какой метод трансплантации наиболее эффективен и какое количество стволовых клеток оптимально. Наше предыдущее исследование было сосредоточено на выяснении преимуществ использования МСK в острой и подострой фазах травмы на модели контузионных крыс [17]. Существующие данные указывают на то, что даже хроническую фазу можно рассматривать как адекватный период для применения клеточной терапии [11-16]. Авторы приводят две основные причины для скорейшего внедрения клеточной терапии: 1) на данный момент не найдено сколько-нибудь эффективного метода лечения хронической ТСМ; 2) микросреда постоянно меняется во время острой/подострой фазы заболевания, в то время как при хронической стадии она относительно стабильна, что позволяет адекватно оценить выживание или дифференцировку трансплантированных клеток. Принимая во внимание выживаемость, миграцию и безопасность трансплантированных клеток, более предпочтительным подходом можно считать интралесальную трансплантацию (в сравнении с интратекальной и внутривенной видами трансплантации) [18-19]. Результаты текущих исследований и клинических испытаний показывают значительный разброс количества используемых МСК: от $4 \cdot 10^{5}$ до $1 \cdot 10^{6}$ в исследованиях на животных [19-22] и от $7 \cdot 10^{5}$ до $2 \cdot 10^{7}$ в клинических испытаниях $[12,14,15,23]$.
Целью данного исследования было проверить ранее предложенную стратегию точной трансплантации MCK и определить оптимальный для лечения хронической ТСМ объем МСК в диапазоне от $4 \cdot 10^{5}$ до $1 \cdot 10^{6}$ кл.

\section{МАТЕРИАЛЫ И МЕТОДЫ}

\section{Инъекция Нч}

Описанными ранее способами получали Н4 [24] и проводили трансплантацию под контролем МРТ [25]. Как правило, крыс анестезировали в течение всей процедуры с помощью E-Z-системы анестезии EZ-7000 330 (РА; США). Мех над зоной Т10 тщательно выбривали, а открытую кожу стерилизовали йодом. Кожу и поверхностную фасцию вскрывали вдоль начального разреза ламинэктомии. Две серебряные иглы для акупунктуры (ОАО «Казанский завод медицинских инструментов»; Россия) вводили через позвоночник. Иглы располагали параллельно поверхности и под углом 40 к позвоночнику, по одной игле с каждой стороны. Кончики игл проходили через мышцы и пересекались друг с другом, создавая крестообразную форму.

По результатам МРТ рассчитывали объем посттравматического свища (ПТС) и его пространственные (3D) координаты с использованием скрещенных игл в качестве контрольной точки. Как поперечное, так и продольное расстояния между ПТС и скрещенными иглами измеряли с помощью программного обеспечения MultiVox Dicom Viewer (верс. R3.0 SP13; СШA). Рассчитывали глубину ПТС.

\section{Группы исследования}

Чтобы доказать точность внутрисвищевой трансплантации, хроническую стадию ТСМ моделировали на взрослых крысax Sprague-Dawley $(n=3)$ весом 180-220 г. Для оценки эфффекта от трансплантации МСK хроническую стадию TCM моделировали на другой группе крыс Sprague-Dawley ( $n=24)$ весом 180-220 г. Этих крыс случайным образом разделили на четыре подгруппы по 6 особей: 1) подгруппа DMEM (по названию среды для культивирования клеток); 2) подгруппа с инъекцией $4 \cdot 10^{5}$ кл.; 3) подгруппа с инъекцией 8 • $10^{5}$ кл.; 4) подгруппа с инъекцией 1 • $10^{6}$ кл.

Эксперимент проводили в соответствии с принципами и требованиями Международной лаборатории по уходу за животными и Директивой совета европейских сообществ (86/609/EЕC) от 24 ноября 1986 г. Были использованы все возможности для сведения к минимуму количества задействованных в эксперименте животных и их страданий.

\section{Получение, культивирование и характеристика стромальных клеток костного мозга}

MCK собирали из костного мозга 4-6-месячных крыс Sprague-Dawley. Биоптат центрифугировали при режиме 300 об./мин 30 мин в градиенте плотности фриколла 1,077 г/мл (Sigma-Aldrich; США) для выделения фракции мононуклеарных клеток. Клетки культивировали в RPMl 1640 (Gibco; CШA) с добавлением 2 мМ глютамина, 100 ед./мл пенициллина, 0,1мг/мл стрептомицина (Gibco; США) и 15\% FBS (Biowest; CША) при $37^{\circ} \mathrm{C}, 5 \% \mathrm{CO}_{2}$. Далее использовали MCK второго-четвертого пассажей. Наличие специфичных маркеров MCK (CD105, CD90 и CD44) и гематопоэтических маркеров (CD45, CD34) подтверждали методом проточной цитометрии с помощью 
клеточного сортера MoFlo (Beckman Coulter; США) с соответствующими первично-меченными антителами (Miltenyi Biotec $\mathrm{GmbH}$; Германия).

Клетки МСК трипсинизировали с помощью 0,25\%-го трипсин-ЭДТА (Invitrogen; Россия) и подсчитывали. Затем готовили 4 аликвоты бессывороточной среды DMEM (Gibco; США), дополненной 2 мМ глутамина, 100 ед./мл пенициллина, 0,1мг/мл стрептомицина (Gibco; CША). Три из них случайным образом отбирали для приготовления клеточной суспензии в различных концентрациях: 1 • $10^{5}$, $2 \cdot 10^{5}$ и 2,5 $\cdot 10^{5}$ кл./МкЛ.

\section{Модель хронической стадии травмы спинного мозга}

Операцию по воссозданию хронической стадии ТСМ выполняли как описано ранее [17]. После внутрибрюшинной анестезии кетамином (50 мг/кг) животных помещали на теплую подкладку в положении лежа и брили мех с дорсальной стороны. Хирургический участок стерилизовали. Чтобы обнажить спинной мозг, выполняли ламинэктомию в сегменте Т9-10. Затем производили ударную нагрузку в 200 килодин на спинной мозг с использованием Impactor PSI-IH, оснащенным датчиками для точного измерения силы удара (Precision Systems and Instrumentation LLC, Fairfax, VA; CШA). После промывания раны холодным физраствором место операции зашивали. Крысам делали подкожную инъекцию Байтрила в дозировке 2,5 мг/кг/сутки (Bayer; США). После операции животных возвращали в их домашние клетки и дважды в день проводили ручное опорожнение мочевого пузыря до восстановления спонтанной функции мочеиспускания.

\section{Стереотактическая трансплантация МСK}

Трансплантацию клеток проводили через 4 ч после травмы [11] под общей анестезией через кожу под контролем МРТ. Для определения местоположения поврежденной области до процедуры трансплантации тоже проводили MPT. C помощью шприца Гамильтона и иглы № 33 с углом наклона 45 (Hamilton, Reno; США) 4 мкл жидкости трансплантировали в область травмы в течение 2 мин с помощью блока микроинъекции и шприцевого насоca Razel NE-1002X (Razel Scientific; США). Затем иглу удерживали в месте инъекции в течение еще 2 мин и медленно извлекали в течение еще 1 мин.

\section{Проведение MPT и DTI}

Всех крыс анестезировали в течение всей процедуры путем ингаляции изофлурана (5DG9621, BAXTER; США) при помощи системы анестезии E-Z (EZ-7000 330, PA; США). В первую и четвертую недели после ТСМ (для оценки зоны повреждения) и на восьмой неделе после ТСМ (для определения эффекта трансплантации МСК) выполняли MPT и DTI-сканирование с использованием семитесловых MPT-сканеров для животных (ClinScan, Bruker BioSpin; США). Для корональных изображений Т2-взвешенные изображения в корональной плоскости были получены с помощью Turbo Spin Echo со следующими параметрами: FOV 120 • 59,2 мм, базовое разрешение 320 • 158, $\mathrm{TR}=3850$ мс, TE = 39 мс, толщина среза 1 мм, количество съемок - 1, длина эхо-последовательности - 9. Для сагиттальных изображений Т2-взвешенные изображения в сагиттальной плоскости были получены с помощью последовательности Turbo Spin Echo co следующими параметрами: FOV 100 • 49,2 мм, базовое разрешение $256 \cdot 126, \mathrm{TR}=3850 \mathrm{mc}, \mathrm{TE}=42 \mathrm{Mc}$, толщина среза $1 \mathrm{mм}$, номер сбора - 3, длина эхосигнала - 9 .

Изображения DTI были получены с такой же геометрией, что и анатомические изображения, с использованием одноэтапной последовательности плоских изображений (EPI) (спиновый эхо-сигнал TR/TE - 4000 мс/88 мс, толщина среза - 3 мм, фактор b - 1000 с/мм², ширина полосы пропускания - 200 кГц, 25 направлений кодирования градиента, матрица сбора данных - 64 • 64 и поле зрения 10 • 10 мм). Для расчета индексов DTI собранные изображения анализировали на независимой рабочей станции. DTT спинного мозга генерировали с использованием алгоритма FACT, реализованного в программном обеспечении Volume-One, в качестве параметров использовали порог дробной анизотропии (FA) <0,2 и угол остановки $>25^{\circ}$.

\section{Макроскопическая оценка зоны поражения}

Макроскопическую оценку проводили через 8 ч после трансплантации клеток каждой крысе. Все животные были гуманно умерщвлены как описано выше. Для удаления возможных компонентов крови из образца проводили внутрисердечную перфузию физиологическим раствором, а затем 4\% параформальдегидом. В качестве биообразцов собирали спинной мозг в области повреждения. Изображения спинного мозга из каждой группы были получены с помощью цифровой камеры (Leica Со.; Германия). С помощью программного обеспечения Image J (Basics 1.38; США) были выбраны участки макроповреждения на поверхности спинного мозга, после чего участки повреждения были рассчитаны автоматически. В каждой группе оценивали и количественно сопоставляли среднюю площадь поражения.

\section{Окрашивание гематоксилин-эозином}

После макроскопической оценки крыс глубоко анестезировали кетамином и ксилазином и перфузировали физиологическим раствором и 4\%-м параформальдегидом в 0,1 М фосфатном буфере. Три образца спинного мозга из каждой группы выбирали случайным образом. Образцы постепенно обезвоживали в 70\%-м, 80\%-м, 90\%-м, 100\%-м этаноле и помещали в ксилол и парафин. Продольные срезы толщиной 10 мкм делали на микротоме роторного типа (Microm HM 650V; США).

Для окрашивания гематоксилин-эозином срезы гидратировали в 100\%-м, 90\%-м, 80\%-м, 70\%-м этаноле (водный раствор), окрашивали в гематоксилине в течение 1 мин, промывали в воде в течение 5 мин с последующим окрашиванием в эозине в течение 1 мин. После покрытия срезов энтеланом оценивали поврежденный участок под световым микроскопом. Среднюю площадь поражения рассчитывали для трех срезов из каждой группы. С помощью программного обеспечения Image J выбирали места повреждения и автоматически рассчитывали зоны поражения. В каждой группе оценивали и количественно сопоставляли среднюю площадь поражения.

\section{Иммуногистохимическое исследование}

Из каждой группы выбирали случайным образом по три образца спинного мозга. Образцы помещали в бусер PBS, продольные срезы толщиной 50 мкм делали на микротоме HM 650V (Thermo Scientific; США). Срезы инкубировали 
с антителами против белка, ассоциированного с микротрубочками 2 (МАР2; мышь анти-крыса; 1 : 400)

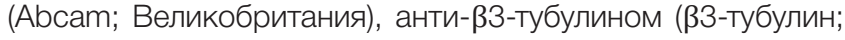
кролик анти-крыса; 1 : 400) (Sigma; США), антителами против глиального фибриллярного кислого белка (GFAP; кролик анти-крыса; 1 : 500) (Abcam; Великобритания), нестином (1 : 400, кролик анти-крыса) (Abcam; Великобритания), нейротрофическим фактором (BDNF; мышь анти-крыса; 1 : 400) (Abcam; Великобритания) и фактором роста эндотелия сосудов (VEGF; мышь антикрыса; 1 : 200) (Abcam; Великобритания) в течение ночи при $4{ }^{\circ} \mathrm{C}$, после чего добавляли TRITC-конъюгированные козьи анти-мышиные или FITC-конъюгированные анти-кроличьи IgG (1 : 200; ZSGB-BIO) и инкубировали в течение часа при $37^{\circ} \mathrm{C}$. Срезы исследовали с помощью конфокального микроскопа Nikon A1 + MP (Nikon; Япония).

Трехмерный график поверхности использовали для полуколичественной оценки флуоресцентных измерений. Теплоую карту образца каждого среза генерировали на основе интенсивности флуоресценции в разных каналах флуоресценции. Тепловая карта образца представляет собой матрицу из трех столбцов, окрашенных от светлоголубого до ярко-красного, и иллюстрирует различные уровни наработки белков.

\section{Анализ поведения}

Локомоторный тест Бассо, Битти и Бреснахана (ВВВ) проводили двойным слепым методом до моделирования травмы и еженедельно посттравматически для оценки восстановления двигательного поведения задних конечностей. Для оценки координации движений проводли тестирование с вращающимся стержнем до того, как крысы были убиты (через 8 ч после трансплантации). Bcex крыс помещали на стандартный Ротарод (Med Associates, Inc.; США) для определения их моторных характеристик. Испытание не проводили в течение всего экспериментального периода, поскольку падение со стержня могло привести к дальнейшим травмам. Каждое животное помещали на стержень диаметром 10 см и длиной 15 см, вращающийся с постоянной скоростью. Нарушение координации движений определяли как неспособность крыс оставаться на вращающемся стержне в течение 60 с испытательного периода. Животные были предварительно обучены на вращающейся дорожке до травмы и повторно обучены за 24 ч до испытания. Протокол испытаний состоял из одного 60-секундного периода испытаний каждые 24 ч в течение 72 ч. В эти непрерывные дни испытывали при 4, 8 и 12 об./мин на 1-й, 2-й и 3-й день соответственно с 10-минутным интервалом между каждым испытанием.

\section{Статистический анализ}

Статистический анализ выполняли с помощью программного пакета SPSS 17.0 (SPSS Inc.; США). Результаты считали статистически значимыми с $p<0,05$. Все данные представляли как среднее значение \pm стандартная ошибка среднего (SEM); использовали повторные измерения ANOVA (RANOVA).

\section{РЕЗУЛЬТАТЫ ИССЛЕДОВАНИЯ}

\section{Точная трансплантация в ПТС}

НЧ показали низкое изменение сигнала при Т2-взвешенном МРТ-сканировании (рис. 1). Трансплантацию НЧ крысам с ПТС проводили в несколько приемов. Как показано на рисунке, зона ПТС значительно сократилась в размерах

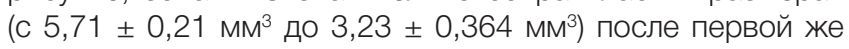
трансплантации ( $p<0,05)$, повторная трансплантация привела к еще большему уменьшению зоны поражения

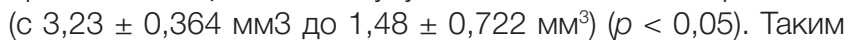
образом, с помощью НЧ удалось продемонстрировать точность предложенного варианта трансплантации.

\section{Общее состояние животных и восстановление моторики}

Ни у одного экспериментального животного не было выявлено признаков осложнений или неожиданной гибели в течение всей процедуры.

До операции показатель ВВВ для всех крыс составлял 21 балл. Сразу после ТСМ все животные продемонстрировали значительную потерю двигательной функции задних конечностей и показатели ВВВ были снижены до 0 баллов (рис. 2). Постепенно показатель ВВВ увеличился во всех группах и через четыре недели
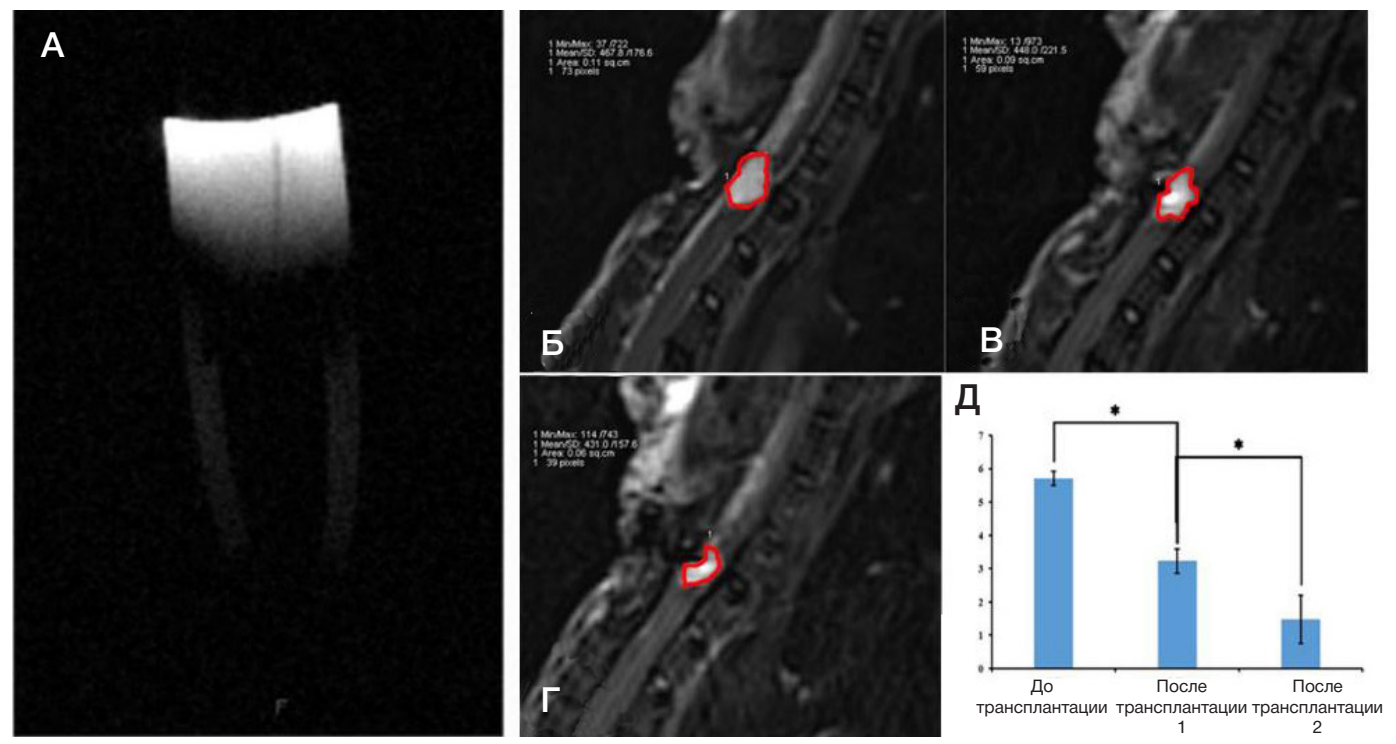

Рис. 1. Трансплантация НЧ и МРТ-анализ. А. НЧ показали низкое изменение сигнала при Т2-взвешенном сканировании. Б-Д. Изменение объема ПТС после трансплантации НЧ. Объем ПТС уменьшился после первой трансплантации и еще сильнее уменьшился после второй трансплантации (р < 0,05) 
после травмы достиг 4,85 \pm 0,83 (группа DMEM), 5,94 \pm 0,74 (группа 4 • $10^{5}$ кл.), 6,08 \pm 0,75 (группа $8 \cdot 10^{5}$ кл.) и 6,02 \pm 0,84 (группа $1 \cdot 10^{6}$ кл.). Различия в показателях BВВ между четырьмя группами не были статистически значимыми до трансплантации клеток.

Через неделю после трансплантации по сравнению с группой DMEM различия были статистически значимыми в группах с трансплантированными клетками (рис. 2М). По сравнению с группой DMEM, поведенческая способность также демонстрировала лучший результат в группах с клеточной терапией. Среди всех групп группа с 1 • $10^{6}$ кл. показала наилучший результат (рис. 2 М). Через восемь недель после трансплантации показатель ВВВ достиг 7,02 \pm 1,36 (группа DMEM), 8,14 $\pm 1,12$ (группа $4 \cdot 10^{5}$ кл.), $10,25 \pm 1,02$ (группа 8 • 105 кл) и 11,07 \pm 1,44 (группа 1 - $10^{6}$ кл.). Крысы демонстрировали различные поведенческие способности в отношении поддержки веса, размещения подошв и подошвенному шаганию (рис. 2A-M).

\section{Уменьшение объема ПТС}

МРТ выполняли на первой и четвертой неделях после травмы, а также на восьмой неделе после трансплантации стволовых клеток костного мозга, при этом оценивали формирование ПТС. В табл. 1 показано число случаев формирования ПТС на разных сроках после травмы.
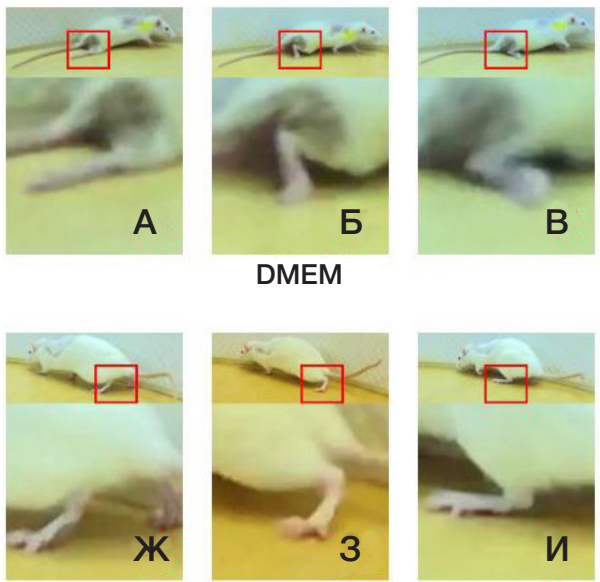

$8 \cdot 10^{5}$
На основе МРТ были рассчитаны объемы ПТС (рис. 4). Размеры ПТС уменьшились в группах после клеточной терапии при оценке через 8 ч после трансплантации. Среди всех групп группа $1 \cdot 10^{6}$ кл. показала наилучшие результаты (рис. ЗУ-Щ).

Для оценки влияния МCK на предотвращение образования рубцов после хронической стадии ТСМ была рассчитана видимая область повреждения. По сравнению с группой DMEM, различия были статистически значимы в группах после клеточной терапии (рис. 4Г). Из всех групп группа 1 • $10^{6}$ кл. показала наилучший результат (рис. 4А-Д).

\section{Оценка восстановительного эффекта для нервной системы}

Чтобы оценить влияние МСK на стимуляцию регенерации и рост нервной ткани, на восьмой неделе после трансплантации клеток были проведены DTI и DTT. B каждой группе были оценены участки дорсальных стволов места поражения (рис. 4 и табл. 2). По сравнению с группой DMEM непрерывность и плотность нервных волокон продемонстрировали улучшение в группах с трансплантированными клетками (рис. 4Б-Г). В группе 1 • $10^{6}$ кл. выявлены наилучшие нервные волокна с полной непрерывностью и высокой плотностью (рис. 4Г). Как показано в табл. 2, для группы 1 • $10^{6}$ кл. коэффициент диффузии поверхности (apparent diffusion coefficient, ADC)
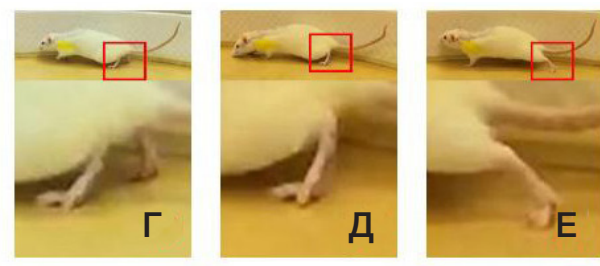

$4 \cdot 10^{5}$
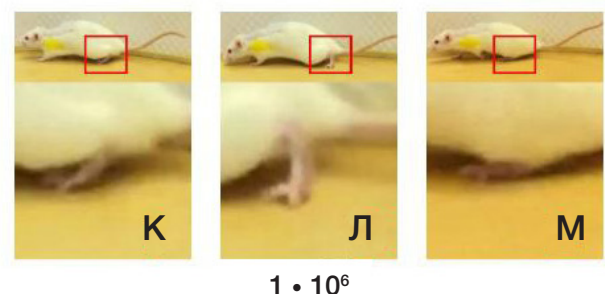

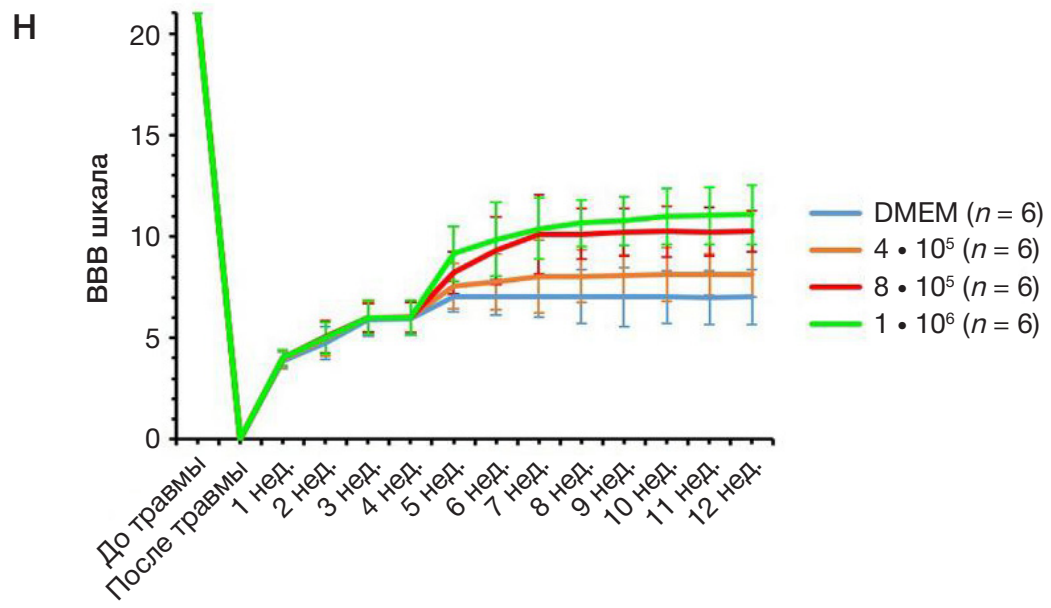

Рис. 2. Восстановление моторной функции с оценкой по шкале ВВВ. Различия в показателях ВВВ между четырьмя группами не были статистически значимыми до трансплантации клеток. Через неделю после трансплантации, по сравнению с группой DMEM, различия были статистически значимыми в группах с трансплантированными клетками $(\mathbf{H})$. По сравнению с группой DMEM, поведенческая способность предполагала лучший результат в группах с трансплантированными клетками. Среди всех групп группа с $1 \cdot 10^{6}$ кл. показала лучший результат (H). Через 8 недель после трансплантации крысы проявляли различные способности по поддержанию веса (А, Г, Ж, К), расположению подошвы (Б, Д, З, Л) и подошвенному шаганию (Б, Е, И, М) 
показал значительное снижение, а величина дробной анизотропии (fractional anisotropy, FA) - значительное увеличение. Таким образом, выявлен эффект зависимости степени регенерации от дозы клеток.

\section{ОБСУЖДЕНИЕ РЕЗУЛЬТАТОВ}

На основании литературных данных, а также результатов нашего исследования, можно предположить, что положительный эфффект от трансплантации МСК зависит от дозы клеток [26]. В данном исследовании была предпринята попытка определить оптимальное для трансплантации

Таблица 1. Число сформировавшихся ПТС в зависимости от срока количество клеток в диапазоне от $4 \cdot 10^{5}$ до $1 \cdot 10^{6}$ кл. Чтобы избежать дополнительного повреждения спинного мозга, использовали высокие концентрации клеток. В ряде работ использовали $1 \cdot 10^{5}, 2 \cdot 10^{5}$ и 2,5 • $10^{5}$ кл./Мкл [19-22]. Ранее было отмечено, что 2,5 • $10^{5}$ кл./мкл — это максимальная концентрация для приготовления МСK. Более высокие значения оказывали негативное влияние на выживаемость клеток и требовал большего калибра инъекционной иглы, что приводило к дополнительному повреждению тканей. Вследствие небольшого объема спинного мозга крысы и необходимости применения среды клеточной суспензии для выживания клеток, в этих

\begin{tabular}{|c|c|c|c|}
\hline & 1 неделя после травмы & 4 недели после травмы & 8 недель после трансплантации \\
\hline группа DMEM & 0 & 3 & 3 \\
\hline группа $4 \cdot 10^{5}$ & 0 & 3 & 3 \\
\hline группа $8 \cdot 10^{5}$ & 0 & 4 & 4 \\
\hline группа $1 \cdot 10^{6}$ & 0 & 4 & 3 \\
\hline
\end{tabular}
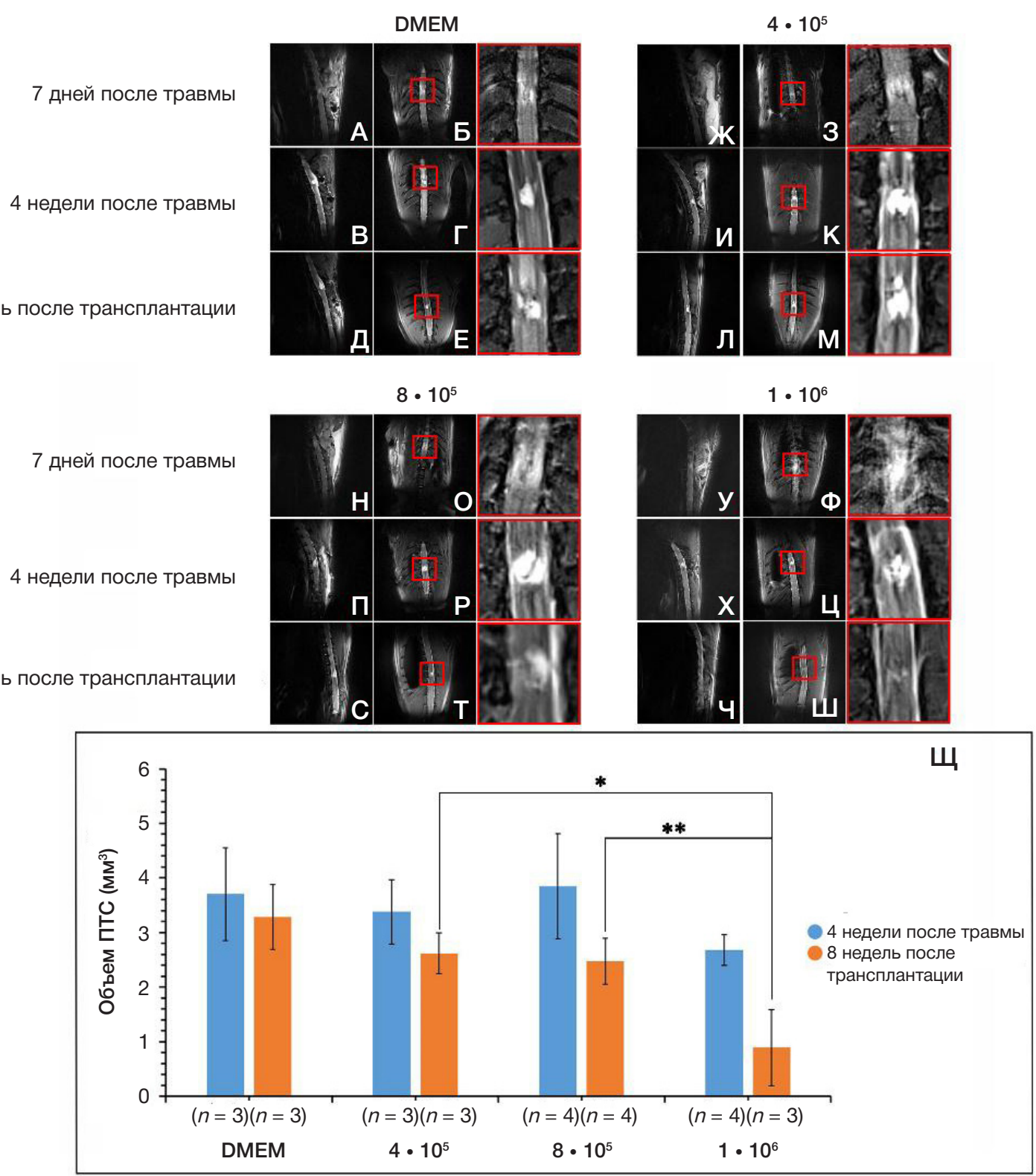

Рис. 3. Сокращение размеров ПТС. Для оценки состояния ПТС до и после трансплантации, во всех группах было выполнено боковое и горизонтальное МРТ-сканирование (А-Ш). Объем ПТС снизился во всех группах с трансплантацией клеток при оценке через 8 ч после трансплантации. Из всех групп группа 1 • $10^{6}$ кл. показала наилучшие результаты (У-Щ). Выделенные красной рамкой области увеличены на рисунках внизу 
DMEM
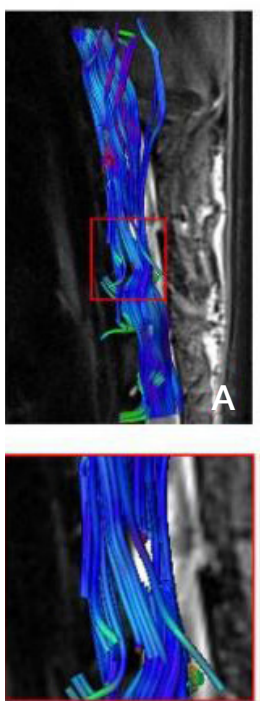

$4 \cdot 10^{5}$
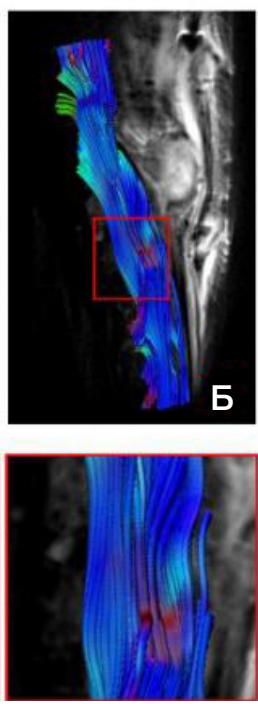

$8 \cdot 10^{5}$
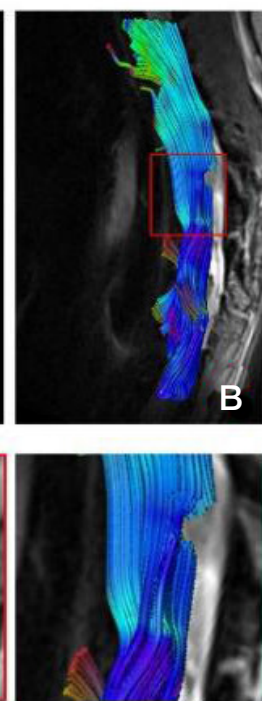

$1 \cdot 10^{6}$
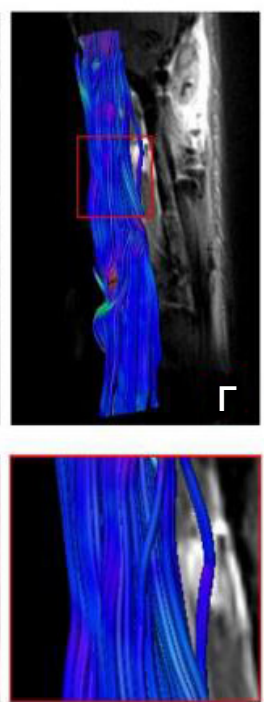

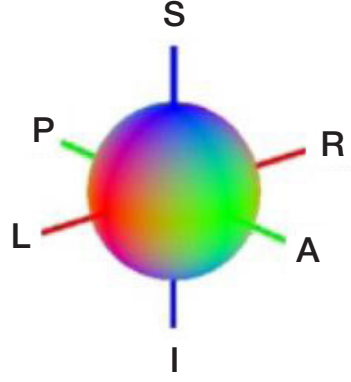

Цветовое обозначение:

Синий: направление вверх-вниз

Красный: направление слева-направо

Зеленый: передне-заднее направление

Рис. 4. Трактографические изображения спинного мозга во всех группах спустя 8 ч после клеточной терапии. На изображении спинного мозга в группе DMEM обнаружен перелом нервных волокон (А). Все группы с трансплантированными клетками продемонстрировали признаки репарации нервных волокон спинного мозга (Б-Г). В группе $1 \cdot 10^{6}$ кл. был достигнут наилучший результат (Г)

Таблица 2. Положение ADC и FA в зоне травмь

\begin{tabular}{|c|c|c|c|c|c|c|c|c|}
\hline \multirow{2}{*}{ Группа } & \multicolumn{2}{|c|}{ DMEM } & \multicolumn{2}{|c|}{$4 \cdot 10^{5} \mathrm{MCK}$} & \multicolumn{2}{|c|}{$8 \cdot 10^{5} \mathrm{MCK}$} & \multicolumn{2}{|c|}{$1 \cdot 10^{6} \mathrm{MCK}$} \\
\hline & ADC & FA & ADC & FA & $A D C$ & FA & $A D C$ & FA \\
\hline $\begin{array}{c}8 \text { недель после } \\
\text { трансплантации }\end{array}$ & $\begin{array}{c}(1792,64 \pm 719,28) \\
\cdot 10^{-6} \mathrm{MM}^{2} / \mathrm{c}\end{array}$ & $0,34 \pm 0,08$ & $\begin{array}{c}(1483,52 \pm 924,91) \\
\cdot 10^{-6} \mathrm{MM}^{2} / \mathrm{c}\end{array}$ & $0,41 \pm 0,10$ & $\begin{array}{c}(1351,77 \pm 1024,55) \\
\cdot 10^{-6} \mathrm{MM}^{2} / \mathrm{c}\end{array}$ & $0,45 \pm 0,09$ & $\begin{array}{c}(1276,39 \pm 1214,84) \\
\cdot 10^{-6} \mathrm{MM}^{2} / \mathrm{c}\end{array}$ & $0,51 \pm 0,12$ \\
\hline
\end{tabular}

работах использовали наименьший возможный объем клеточной суспензии, равный 4 мкл [19-22].

Были разработаны различные стратегии трансплантации клеток в спинной мозг, включая доставку в очаг поражения, доставку в одну точку с различными интервалами, доставку в несколько мишеней и доставку последовательно в два подхода [26-28]. При планировании пути введения следует учитывать четыре фактора: 1) в область поражения, как правило, можно ввести больший объем клеток, тогда как в нормальные ткани обычно входит меньше клеток; 2) более высокие показатели выживаемости клеток; 3) подход, который можно точно повторить для каждой особи; 4) минимизацию урона. Таким образом, основываясь на наших предыдущих публикациях, в настоящем исследовании мы использовали локальное поражение места доставки клеток [25].

В нескольких исследованиях показано, что трансплантация MCK улучшала результат после ТСМ [19-22]. По нашим результатам, трансплантация МСK может стимулировать регенерацию и прорастание аксонов, улучшать восстановление двигательной функции, уменьшать образование ПТС и глиального рубца, способствовать васкуляризации и экспрессии нейротрофического фактора. Нами установлено, что группа 1 • 106 кл. показала наилучший результат среди всех групп. Можно предположить, что чем больше задействованных клеток, тем лучше получаемый эффект. Сообщалось также, что одним из основных механизмов трансплантации МСК при лечении хронической стадии TСМ является паракринный эффект МСK [11]. Поэтому мы предположили, что чем больше клеточная доза, тем больше привнесено трофических факторов. Как продемонстрировано в настоящем исследовании методами иммуногистохимии, уровни экспрессии BDNF и VEGF в месте поражения среди всех групп были наивысшими после трансплантации 1 • $10^{6}$ кл., тогда как после трансплантации 4 • $10^{5}$ и 8 • $10^{5}$ кл. экспрессия BDNF и VEGF возрастала (относительно группы DMEM) в меньшей степени. До настоящего времени не было проведено количественной оценки изменения трофических факторов после хронической стадии ТСМ или детального количества желаемых трофических факторов для лечения ТСМ. Данное исследование показало, что чем больше задействованных клеток и чем выше трофические факторы экспрессии, тем быстрее и лучше достигается восстановление поведения. Тем не менее при увеличении объема и/или концентрации клеток следует соблюдать осторожность, чтобы избежать дополнительного ущерба.

K недостаткам настоящего исследования можно отнести то, что мы не оценивали показатели выживаемости трансплантированных МСK, в связи с чем запланированы дальнейшие исследования по оценке выживаемости и клеточного апоптоза.

\section{ВЫВОДЫ}

Клеточная терапия с помощью МСК при хронической стадии ТСМ является безопасной стратегией в пределах концентраций $1 \cdot 10^{5}, 2 \cdot 10^{5}$ и 2,5 $10^{5}$ кл./мкл и с общим числом клеток $4 \cdot 10^{5}, 8 \cdot 10^{5}$ и $1 \cdot 10^{6}$ на зону поражения. В настоящем исследовании MCK in vivo могут восстанавливать функцию после ТСМ в хронической стадии посредством стимуляции регенерации и прорастания аксонов, улучшения восстановления двигательной функции, уменьшения образования ПТС и глиального рубца, стимуляции васкуляризации и экспрессии нейротрофического фактора. Выявленный эффект зависел от количества клеток, причем наилучшей дозой оказалось $1 \cdot 10^{6}$ кл. В то же время комбинированное применение DTI и DTT могло бы стать стратегией для количественной оценки ситуации с ПТС после хронической стадии ТСМ. 


\section{Литература}

1. Ning GZ, Yu TQ, Feng $S Q$, Zhou $X H$, Ban DX, Liu $Y$ et al. Epidemiology of traumatic spinal cord injury in Tianjin, China. Spinal Cord. 2011; (49): 386-90.

2. Furlan JC, Sakakibara BM, Miller WC, Krassioukov AV. Global incidence and prevalence of traumatic spinal cord injury. Can $J$ Neurol Sci. 2014; (40): 456-64.

3. Oliveri RS, Bello S, Biering-Sørensen F. Mesenchymal stem cells improve locomotor recovery in traumatic spinal cord injury: systematic review with meta-analyses of rat models. Neurobiol Dis. 2014; (62): 338-53.

4. Devivo M. Epidemiology of traumatic spinal cord injury: Trends and future implications. Spinal Cord. 2012; (50): 365-72.

5. Siddiqui AM, Khazaei M, Fehlings MG. Translating mechanisms of neuroprotection, regeneration, and repair to treatment of spinal cord injury. Prog Brain Res. 2015; (218): 15-54.

6. Salewski RP, Mitchell RA, Li L, Shen C, Milekovskaia M, Nagy A et al. Transplantation of Induced Pluripotent Stem Cell-Derived Neural Stem Cells Mediate Functional Recovery Following Thoracic Spinal Cord Injury Through Remyelination of Axons. Stem Cells Transl Med. 2015; (4): 743-54.

7. Raspa A, Pugliese R, Maleki M, Gelain F. Recent therapeutic approaches for spinal cord injury. Biotechnol Bioeng. 2016; (113): 253-9.

8. Boido M, Garbossa D, Fontanella M, Ducati A, Vercelli A Mesenchymal stem cell transplantation reduces glial cyst and improves functional outcome after spinal cord compression. World Neurosurg. 2014; (81): 183-90.

9. Caplan Al. Mesenchymal stem cells. J Orthop Res. 1991; (9): 641-50.

10. U.S. National Institutes of Health. Clinical trials. Available from: https://clinicaltrials.gov/.

11. de Almeida FM, Marques SA, Ramalho Bdos S, Massoto TB, Martinez AM. Chronic spinal cord lesions respond positively to tranplants of mesenchymal stem cells. Restor Neurol Neurosci. 2015; (33): 43-55.

12. Mendonça MV, Larocca TF, de Freitas Souza BS, Villarreal CF, Silva LF, Matos AC et al. Safety and neurological assessments after autologous transplantation of bone marrow mesenchymal stem cells in subjects with chronic spinal cord injury. Stem Cell Res Ther. 2014; (5): 126.

13. Lee SH, Kim Y, Rhew D, Kuk M, Kim M, Kim WH et al. Effect of the combination of mesenchymal stromal cells and chondroitinase ABC on chronic spinal cord injury. Cytotherapy. 2015; (17): 1374-83.

14. Amr SM, Gouda A, Koptan WT, Galal AA, Abdel-Fattah DS, Rashed LA et al. Bridging defects in chronic spinal cord injury using peripheral nerve grafts combined with a chitosan-laminin scaffold and enhancing regeneration through them by cotransplantation with bone-marrow-derived mesenchymal stem cells: case series of 14 patients. J Spinal Cord Med. 2014; (37): 54-71.

15. Dai G, Liu X, Zhang Z, Yang Z, Dai Y, Xu R. Transplantation of autologous bone marrow mesenchymal stem cells in the treatment of complete and chronic cervical spinal cord injury. Brain Res. 2013; (1533): 73-9.

\section{References}

1. Ning GZ, Yu TQ, Feng SQ, Zhou XH, Ban DX, Liu $Y$ et al. Epidemiology of traumatic spinal cord injury in Tianjin, China. Spinal Cord. 2011; (49): 386-90.

2. Furlan JC, Sakakibara BM, Miller WC, Krassioukov AV. Global incidence and prevalence of traumatic spinal cord injury. Can $J$ Neurol Sci. 2014; (40): 456-64.

3. Oliveri RS, Bello S, Biering-Sørensen F. Mesenchymal stem cells improve locomotor recovery in traumatic spinal cord injury: systematic review with meta-analyses of rat models. Neurobiol Dis. 2014; (62): 338-53.

4. Devivo M. Epidemiology of traumatic spinal cord injury: Trends and future implications. Spinal Cord. 2012; (50): 365-72.

5. Siddiqui AM, Khazaei M, Fehlings MG. Translating mechanisms of neuroprotection, regeneration, and repair to treatment of spinal cord injury. Prog Brain Res. 2015; (218): 15-54.
16. Hodgetts SI, Simmons PJ, Plant GW. A comparison of the behavioral and anatomical outcomes in sub-acute and chronic spinal cord injury models following treatment with human mesenchymal precursor cell transplantation and recombinant decorin. Exp Neurol. 2013; (248): 343-9.

17. Ning G, Tang L, Wu Q, Li Y, Li Y, Zhang $C$ et al. Human umbilical cord blood stem cells for spinal cord injury: early transplantation results in better local angiogenesis. Regen Med. 2013; (8): 271-81.

18. Takahashi Y, Tsuji O, Kumagai G, Hara CM, Okano HJ, Miyawaki A et al. Comparative study of methods for administering neural stem progenitor cells to treat spinal cord injury in mice. Cell Transplant. 2011; (20): 727-39.

19. Kim JW, Ha KY, Molon JN, Kim YH. Bone marrow-derived mesenchymal stem cell transplantation for chronic spinal cord injury in rats: comparative study between intralesional and intravenous transplantation. Spine (Phila Pa 1976). 2013; (38): E1065-74.

20. Amemori T, Jendelová P, Růzicková K, Arboleda D, Syková E. Cotransplantation of olfactory ensheathing glia and mesenchymal stromal cells does not have synergistic effects after spinal cord injury in the rat. Cytotherapy. 2010; (12): 212-25.

21. Kang KN, Kim DY, Yoon SM, Lee JY, Lee BN, Kwon JS et al. Tissue engineered regeneration of completely transected spinal cord using human mesenchymal stem cells. Biomaterials. 2012; (33): 4828-35.

22. Kumagai G, Tsoulfas P, Toh S, McNiece I, Bramlett HM, Dietrich WD. Genetically modified mesenchymal stem cells (MSCs) promote axonal regeneration and prevent hypersensitivity after spinal cord injury. Exp Neurol. 2013; (248): 369-80.

23. Karamouzian S, Nematollahi-Mahani SN, Nakhaee N, Eskandary H. Clinical safety and primary efficacy of bone marrow mesenchymal cell transplantation in subacute spinal cord injured patients. Clin Neurol Neurosurg. 2012; (114): 935-9.

24. Abakumov MA, Nukolova NV, Sokolsky-Papkov M, et al. VEGFtargeted magnetic nanoparticles for MRI visualization of brain tumor. Nanomedicine. 2015; 11 (4): 825-33.

25. Zhang C, Morozova AY, Abakumov MA, Gubsky IL, Douglas P, Feng $S$ et al. Precise Delivery Into Chronic Spinal Cord Injury Syringomyelic Cysts with Magnetic Nanoparticles MRI Visualization. Med Sci Monit. 2015; (21): 3179-85.

26. Cigognini D, Satta $A$, Colleoni $B$, Silva $D$, Donegà $M$, Antonini S et al. Evaluation of early and late effects into the acute spinal cord injury of an injectable functionalized self-assembling scaffold. PLoS One. 2011; (6): e1978.

27. Mannoji C, Koda M, Kamiya K, Dezawa M, Hashimoto M, Furuya T et al. Transplantation of human bone marrow stromal cell-derived neuroregenrative cells promotes functional recovery after spinal cord injury in mice. Acta Neurobiol Exp (Wars). 2014; (74): 479-88.

28. Rao YJ, Zhu WX, Du ZQ, Jia CX, Du TX, Zhao QA et al. Effectiveness of olfactory ensheathing cell transplantation for treatment of spinal cord injury. Genet Mol Res. 2014; (13): 4124-9.

6. Salewski RP, Mitchell RA, Li L, Shen C, Milekovskaia M, Nagy A et al. Transplantation of Induced Pluripotent Stem Cell-Derived Neural Stem Cells Mediate Functional Recovery Following Thoracic Spinal Cord Injury Through Remyelination of Axons. Stem Cells Transl Med. 2015; (4): 743-54.

7. Raspa A, Pugliese R, Maleki M, Gelain F. Recent therapeutic approaches for spinal cord injury. Biotechnol Bioeng. 2016; (113): 253-9.

8. Boido M, Garbossa D, Fontanella M, Ducati A, Vercelli A Mesenchymal stem cell transplantation reduces glial cyst and improves functional outcome after spinal cord compression. World Neurosurg. 2014; (81): 183-90.

9. Caplan Al. Mesenchymal stem cells. J Orthop Res. 1991; (9): 641-50.

10. U.S. National Institutes of Health. Clinical trials. Available from: https://clinicaltrials.gov/.

11. de Almeida FM, Marques SA, Ramalho Bdos S, Massoto TB, 
Martinez AM. Chronic spinal cord lesions respond positively to tranplants of mesenchymal stem cells. Restor Neurol Neurosci. 2015; (33): 43-55.

12. Mendonça MV, Larocca TF, de Freitas Souza BS, Villarreal CF, Silva LF, Matos AC et al. Safety and neurological assessments after autologous transplantation of bone marrow mesenchymal stem cells in subjects with chronic spinal cord injury. Stem Cell Res Ther. 2014; (5): 126.

13. Lee SH, Kim Y, Rhew D, Kuk M, Kim M, Kim WH et al. Effect of the combination of mesenchymal stromal cells and chondroitinase ABC on chronic spinal cord injury. Cytotherapy. 2015; (17): 1374-83.

14. Amr SM, Gouda A, Koptan WT, Galal AA, Abdel-Fattah DS, Rashed LA et al. Bridging defects in chronic spinal cord injury using peripheral nerve grafts combined with a chitosan-laminin scaffold and enhancing regeneration through them by cotransplantation with bone-marrow-derived mesenchymal stem cells: case series of 14 patients. J Spinal Cord Med. 2014; (37): 54-71.

15. Dai G, Liu X, Zhang Z, Yang Z, Dai Y, Xu R. Transplantation of autologous bone marrow mesenchymal stem cells in the treatment of complete and chronic cervical spinal cord injury. Brain Res. 2013; (1533): 73-9.

16. Hodgetts SI, Simmons PJ, Plant GW. A comparison of the behavioral and anatomical outcomes in sub-acute and chronic spinal cord injury models following treatment with human mesenchymal precursor cell transplantation and recombinant decorin. Exp Neurol. 2013; (248): 343-9.

17. Ning G, Tang L, Wu Q, Li Y, Li Y, Zhang $C$ et al. Human umbilical cord blood stem cells for spinal cord injury: early transplantation results in better local angiogenesis. Regen Med. 2013; (8): 271-81.

18. Takahashi $Y$, Tsuji O, Kumagai G, Hara CM, Okano HJ, Miyawaki A et al. Comparative study of methods for administering neural stem/ progenitor cells to treat spinal cord injury in mice. Cell Transplant. 2011; (20): 727-39.

19. Kim JW, Ha KY, Molon JN, Kim YH. Bone marrow-derived mesenchymal stem cell transplantation for chronic spinal cord injury in rats: comparative study between intralesional and intravenous transplantation. Spine (Phila Pa 1976). 2013; (38): E1065-74.

20. Amemori T, Jendelová P, Růzicková K, Arboleda D, Syková E. Cotransplantation of olfactory ensheathing glia and mesenchymal stromal cells does not have synergistic effects after spinal cord injury in the rat. Cytotherapy. 2010; (12): 212-25.

21. Kang KN, Kim DY, Yoon SM, Lee JY, Lee BN, Kwon JS et al. Tissue engineered regeneration of completely transected spinal cord using human mesenchymal stem cells. Biomaterials. 2012; (33): 4828-35.

22. Kumagai G, Tsoulfas P, Toh S, McNiece I, Bramlett HM, Dietrich WD. Genetically modified mesenchymal stem cells (MSCs) promote axonal regeneration and prevent hypersensitivity after spinal cord injury. Exp Neurol. 2013; (248): 369-80.

23. Karamouzian S, Nematollahi-Mahani SN, Nakhaee N, Eskandary H. Clinical safety and primary efficacy of bone marrow mesenchymal cell transplantation in subacute spinal cord injured patients. Clin Neurol Neurosurg. 2012; (114): 935-9.

24. Abakumov MA, Nukolova NV, Sokolsky-Papkov M, et al. VEGFtargeted magnetic nanoparticles for MRI visualization of brain tumor. Nanomedicine. 2015; 11 (4): 825-33.

25. Zhang C, Morozova AY, Abakumov MA, Gubsky IL, Douglas P, Feng $S$ et al. Precise Delivery Into Chronic Spinal Cord Injury Syringomyelic Cysts with Magnetic Nanoparticles MRI Visualization. Med Sci Monit. 2015; (21): 3179-85.

26. Cigognini D, Satta A, Colleoni B, Silva D, Donegà M, Antonini S et al. Evaluation of early and late effects into the acute spinal cord injury of an injectable functionalized self-assembling scaffold. PLoS One. 2011; (6): e1978.

27. Mannoji C, Koda M, Kamiya K, Dezawa M, Hashimoto M, Furuya T et al. Transplantation of human bone marrow stromal cell-derived neuroregenrative cells promotes functional recovery after spinal cord injury in mice. Acta Neurobiol Exp (Wars). 2014; (74): 479-88.

28. Rao YJ, Zhu WX, Du ZQ, Jia CX, Du TX, Zhao QA et al. Effectiveness of olfactory ensheathing cell transplantation for treatment of spinal cord injury. Genet Mol Res. 2014; (13): 4124-9. 